「26th Annual Conference Proceeding」

\title{
Portable License Plate Recognition System on Android devices: Case study Law enforcement in Tanzania
}

\begin{abstract}
Katunda, Ramadhani ${ }^{1 *}$
1 Graduate School of Information Technology,

Kobe Institute of Computing Kobe, Japan

Email: s16157@st.kic.ac.jp

Abstract: The use of License Plate Recognition Systems (LPR) has proved to be important in the detection of many offences, including locating stolen vehicles, tackling uninsured vehicle use and solving cases of terrorism, major and organized crime. The current existing ALPR solutions in the market are very expensive and require a high level of connectivity which means many developing countries including Tanzania cannot deploy such systems to to limited funds and poor network communication infrastructure. In this paper, the portable LPR implemented on Android is presented as a means of reducing the total cost of acquiring such technology while still offering high standards of image recognition and processing.
\end{abstract}

Keywords: License Plate Recognition (LPR) Optical Character Recognition (OCR)

\section{INTRODUCTION}

The United Republic of Tanzania, located in East Africa, is low income and is classified as a developing economy, however it has sustained relatively high economic growth over the last decade (World Bank, 2017). Due to growth and expansion of the economy, there has been a significant increase in land transportation infrastructure (road networks and vehicles). Unfortunately, this increase has not been on par with road safety literacy and training among those road users. This problem goes hand-in hand with the lack of significant government investment in road safety and security enforcement.
Between the years 2014 and 2015, 10,549 vehicles and 915 Motorcycles were reported stolen in the country, During the same period, there were 24,197 major traffic offence cases reported nationwide (National Bureau of Statistics, 2016). Currently the road safety and traffic department of the Tanzania Police Force do not use any ICT infrastructure to help them monitor roads and vehicles, not even the use of CCTV video surveillance. The current method used is "manual" whereby they have to stop vehicles randomly to check whether they comply with the law or they are breaking it. This reveals the following massive loopholes and problems at hand: 
1.During a police stop, it is not easy to immediately identify a vehicle with expired road license, driver's license and Insurance. If the documents or number plates are forged there is no quick way of knowing. Also Road license/insurance evasion and unpaid fines means loss of much needed funds for government and drivers who don't have proper licenses/training contribute to high road accidents and death.

2.If a vehicle is stolen or wanted in connection with a crime (such a bank robbery, hit-and-run etc.) there is no easy way of knowing so.

3.If the vehicle was stolen overseas or is wanted in connection with an investigation from INTERPOL, there is no easy way of identifying it.

The current challenges being faced in road safety and security can greatly be reduced by implementing License Plate Recognition Systems, however the cost of implementing such systems are very expensive especially for a developing country like Tanzania. Given the high hardware and software cost of acquisition of such systems, the scope and objective of this this paper is to propose a low-cost LPR system using Android mobile device while while still offering high standards of image recognition and processing.

The subsequent parts of the paper are organized as follows: Chapter 2 discusses the LPR Systems and Procesess, Chapter 3 discusses the System Design and implementation and Chapter 4 will present the Experiment and Verification thus concluding with Chapter 5 discussing limitations and future work.

\section{License Plate Recognition SySTEMS}

\subsection{Background of LPR Systems}

LPR is an image processing technology used to identify number plates using OCR Optical Character Recognition (Shaaban, 2011). LPR plays an important role in maintaining law enforcement and maintaining traffic rules. It has wide applications areas such as toll plaza, parking area, highly security areas and boarder enforcement. LPR is designed to identify the number plate and then recognize the vehicle number plate from a moving vehicle automatically. As a vehicle passes an LPR camera, its registration number is read and instantly checked against database records of wanted or blacklisted vehicles. If the vehicle is listed as wanted, police officers can intercept and stop a vehicle, check it for evidence and, where necessary, make arrests.

\subsection{The LPR Process}

LPR systems commonly work in five steps which include (i) image acquisition, (ii) image pre-processing, (iii) Number Plate Localization, (iv) Character Segmentation to get individual characters and finally (v) Optical Character Recognition (OCR). 
During Image Acquisition, the following steps are performed; Image Capturing, Image Resizing, Image Color Conversion, Image Smoothing. After performing the steps 1-4, the image is passed to next component. (Liaqat, 2011). The license plate is detected on and extracted from the image and Character Segmentation is done on that extracted license plate. The segmented characters are then passed to OCR engine and the OCR engine returns these segmented characters in text format. In the last step, data in text format is matched in database and the result is displayed on the mobile screen.

\section{System DESIGN AND IMPLEMENTATION}

\subsection{Overall Requirments}

The proposed application should fulfill the following requirements:

1.Read the standard Tanzanian and UK license plate. The UK plates are sampled because most reported stolen vehicles from abroad that arrive in Tanzania are from that region (National Bureau of Statistics, 2016).

2. Maximum expected distance between car and camera: 5 meters.

3. Minimum Camera angle: 90 degrees (facing straight at the license plate).
5.Minimum Camera resolution: 3 Mega Pixel.

\subsection{Software development}

The prosed system is designed and implemented using Android Studio which is the official Integrated Development Environment (IDE) for Android app development, based on IntelliJ IDEA. On top of IntelliJ's powerful code editor and developer tools, Android Studio offers even more features that enhance productivity when building Android apps, such as a flexible Gradle-based build system, a fast and feature-rich emulator and a unified environment where you can develop for all Android devices. The databases are created and maintained into SQL Server. (Android, 2018)

\subsection{Device requirements}

\begin{tabular}{|c|c|c|}
\hline Device & $\begin{array}{l}\text { Hardware } \\
\text { Specification }\end{array}$ & $\begin{array}{l}\text { Software } \\
\text { Specification }\end{array}$ \\
\hline Laptop & $\begin{array}{ll}- & \text { I5 } \\
& \text { Processor } \\
- & 8 \text { GB RAM } \\
- & 250 \quad \text { GB } \\
& \text { Hard Disk }\end{array}$ & $\begin{array}{ll}\text { - } & \text { Windows } \\
& 10 \\
\text { - } & \text { Java } \\
\text { - } & \text { Android } \\
& \text { Studio } \\
\text { - } & \text { Visual } \\
& \text { Studio }\end{array}$ \\
\hline $\begin{array}{l}\text { Android } \\
\text { Device }\end{array}$ & $\begin{array}{l}\text { - } 1 \text { GB RAM } \\
-1.2 \text { Quad } \\
\text { core } \\
\text { processor }\end{array}$ & $\begin{array}{ll}- & \text { Android } \\
& \text { v6.0 }\end{array}$ \\
\hline
\end{tabular}

Table 1: Hardware requirements

4. Works properly in daylight. 


\subsection{Proposed system architecture}

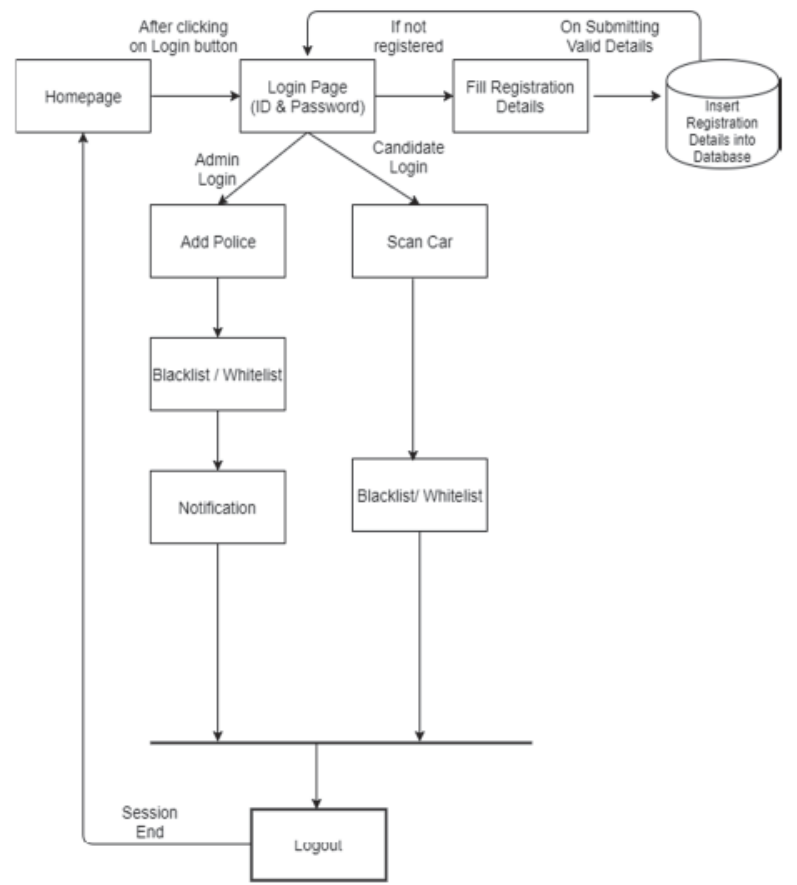

(Figure 1) System Architecture

\subsection{Implementation}

The prototype was developed successfully and
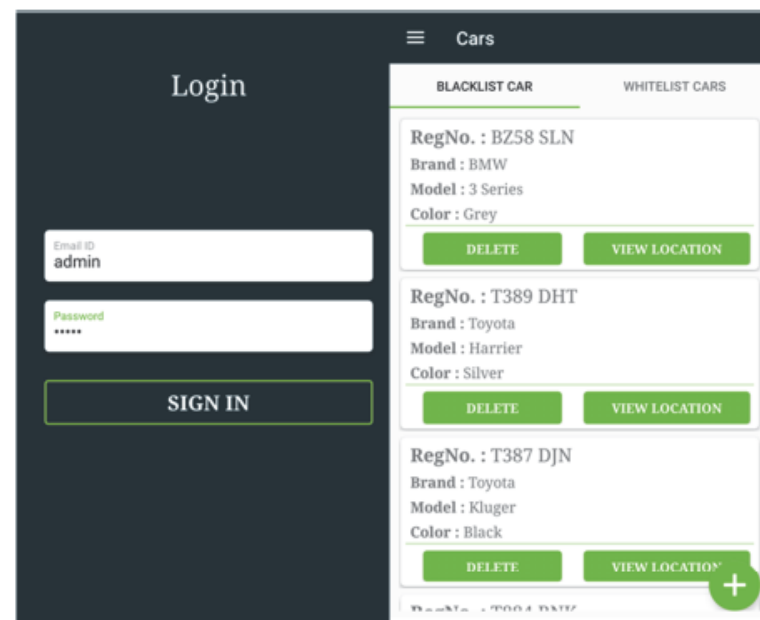

1. Login Page for Admin and Police offices are.
2. Admin page for

Blacklisting or Whitelisting a vehicle. The vehicles last seen location can be views

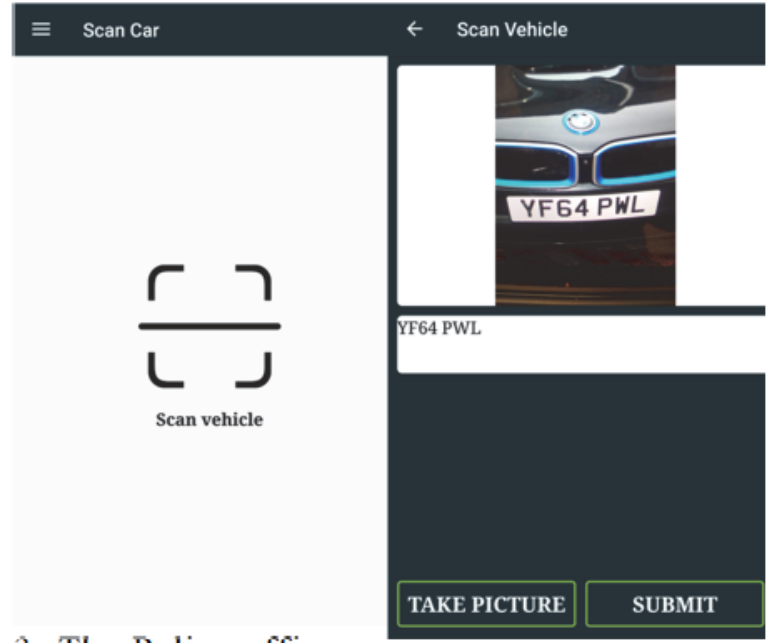

3. The Police officer presses the "Scan Vehicle" button and aligns the License plate for picture

4. The license plate is read succesfully and when he/she clicks submit, it will display if it is blaclisted or whitelisted as well as GPS location.

(Figure 2) Implementation of prototype

\section{VERIFICATION}

Experiments have been performed to evaluate the proposed Android LPR System to measure and verify the accuracy and effectiveness of the system. The sample images used were based on Tanzanian license plates and UK license plates which a both similar in character, layout and design.

Table 2 below displays the results whereby the recognition accuracy was found to be $86.67 \%$ and the average time taken to recognize the number plate is $\mathbf{2 . 1 8}$ seconds.

\begin{tabular}{|l|l|l|l|}
\hline$\#$ & $\begin{array}{l}\text { Number } \\
\text { Plate }\end{array}$ & $\begin{array}{l}\text { Result } \\
\text { (Fail/Success) }\end{array}$ & $\begin{array}{l}\text { Time } \\
(\mathrm{s})\end{array}$ \\
\hline 1 & $\begin{array}{l}\text { T644 } \\
\text { CFC }\end{array}$ & Success & 2.0 \\
\hline 2 & $\begin{array}{l}\text { T844 } \\
\text { BCX }\end{array}$ & Success & 2.1 \\
\hline
\end{tabular}




\begin{tabular}{|l|l|l|l|}
\hline 3 & $\begin{array}{l}\text { OY17 } \\
\text { LKK }\end{array}$ & Success & 2.3 \\
\hline 4 & $\begin{array}{l}\text { T255 } \\
\text { AQY }\end{array}$ & Fail & 1.9 \\
\hline 5 & $\begin{array}{l}\text { YF64 } \\
\text { PWL }\end{array}$ & Success & 2.1 \\
\hline 6 & $\begin{array}{l}\text { UK65 } \\
\text { FCV }\end{array}$ & Success & 3.2 \\
\hline 7 & $\begin{array}{l}\text { T783 } \\
\text { AJY }\end{array}$ & Success & 1.8 \\
\hline 8 & $\begin{array}{l}\text { T567 } \\
\text { CSE }\end{array}$ & Success & 2.2 \\
\hline 9 & T988 CJK & Success & 1.7 \\
\hline 10 & $\begin{array}{l}\text { T143 } \\
\text { BRT }\end{array}$ & Success & 2.8 \\
\hline 11 & $\begin{array}{l}\text { T478 } \\
\text { AUY }\end{array}$ & Success & 1.9 \\
\hline 12 & $\begin{array}{l}\text { T194 } \\
\text { ABC }\end{array}$ & Success & 2.5 \\
\hline 13 & $\begin{array}{l}\text { T432 } \\
\text { DBU }\end{array}$ & Success & 2.0 \\
\hline 14 & T854 BIO & Fail & 2.4 \\
\hline 15 & $\begin{array}{l}\text { T875 } \\
\text { BYT }\end{array}$ & Success & 1.8 \\
\hline
\end{tabular}

(Table 2) OCR test reults

Summary of findings:

Total Numbers of Extracted License Plates: 15

Correct OCR Results: 13

Precision of LPR OCR: $\mathbf{8 6 . 6 7 \%}$

Average time taken to get result: 2.18 Seconds

\section{Conclusion}

This paper has discussed the development of a portable LPR using and Android enabled mobile phone. The use of Android and open source has potential to help developing countries develop and acquire such much needed systems at a lowered cost while still delivering high quality results. To evaluate the performance, the application is tested over several license plated from Tanzania and the UK, giving very good accuracy of $86.67 \%$. The limitations of the system presented are that it currently doesn't work using live feed, rather the user must capture the plate image for the result to be shown, this can be improved upon in future work.7.

\section{REFERENCES}

[1] National Bureau of Statistics Ministry of Finance and Planning, "CRIME AND TRAFFIC INCIDENTS STATISTICS REPORT", National Bureau of Statistics, 2016.

[2] "The World Bank In Tanzania", World Bank, 2018. [Online]. Available: http://www.worldbank.org/en/country/tanza nia/overview. [Accessed: 02- Apr- 2018].

[3] Ling Liu, Xinghui Zhang, "Study on Intelligent License Plate Recognition System", Chinese Journal of Scientific Instrument, 2004

[4] "Meet Android Studio | Android Studio", Android Studio, 2018. [Online]. Available: https://developer.android.com/studio/intro/i ndex.html. [Accessed: 01- Apr- 2018]. 
情報知識学会誌 2018 Vol. 28, No. 2

[5] Zyad Shaaban, An Intelligent License

Plate Recognition System, IJCSNS

International Journal of Computer Science

and Network Security, VOL.11 No.7, July

2011

[6] A. Liaqat, "Mobile Real-Time License

Plate Recognition", Postgraduate, Linnaeus

University, 2011. 